\title{
Correction to: Textural Quantification and Classification of Drill Cores for Geometallurgy: Moving Toward 3D with X-ray Microcomputed Tomography ( $\mu \mathrm{CT})$
}

\author{
Pratama Istiadi Guntoro $\stackrel{10,3}{1,3}$ Yousef Ghorbani, ${ }^{1}$ Alan R. Butcher, ${ }^{2}$ Jukka Kuva, ${ }^{2}$ \\ and Jan Rosenkranz ${ }^{1}$
}

Correction to: Natural Resources Research

https://doi.org/10.1007/s11053-020-09685-5

The original version of the article unfortunately contained an error in Table 9.
In article PDF, Table 7 was inadvertently repeated in place of Table 9 instead of placing the appropriate table. However, the article available online is correct.

The correct Table 9 is presented here:

Table 9. Drill core classification performance with AIM-RF. Overall accuracy of the scheme is $84 \%$

\begin{tabular}{|l|l|l|l|}
\hline \multirow{2}{*}{ True class } & \multicolumn{3}{|c|}{ Predicted class } \\
\cline { 2 - 4 } & Sample A & Sample B & Sample C \\
\hline Sample A & $80 \%$ & $14 \%$ & $6 \%$ \\
\hline Sample B & $12 \%$ & $84 \%$ & $5 \%$ \\
\hline Sample C & $9 \%$ & $4 \%$ & $88 \%$ \\
\hline
\end{tabular}

The original article has been corrected.

${ }^{1}$ Division of Minerals and Metallurgical Engineering, Luleå University of Technology, 971 87, Luleå, Sweden.

${ }^{2}$ Geological Survey of Finland GTK, PO Box 9602151 Espoo, Finland.

${ }^{3}$ To whom correspondence should be addressed; e-mail: pratama.istiadi.guntoro@ltu.se

The original article can be found online at https://doi.org/10.1007/ s11053-020-09685-5.

Publisher's Note Springer Nature remains neutral with regard to jurisdictional claims in published maps and institutional affiliations. 